\title{
Relative Rates of Transcapillary Movement of Free Thyroxine, Protein-Bound Thyroxine, Thyroxine-Binding Proteins, and Albumin
}

\author{
Clifford H. G. Irvine and M. W. Simpson-Morgan \\ From the Department of Animal Physiology, Lincoln College, New Zealand and \\ John Curtin Medical School, Australian National University, \\ Canberra, Australia
}

A B S T R A C T The rate of appearance of labeled thyroxine (T4) and albumin in lymph from various areas after simultaneous i.v. injection of the labeled substances in conscious ambulatory sheep has been used to estimate the relative rates of transcapillary movement of stable $\mathrm{T} 4$ and albumin. Labeled T4 appeared in hepatic lymph at the same rate as albumin. In intestinal and leg lymph, labeled T4 appeared eight and four times as rapidly as albumin indicating that $\mathrm{T} 4$ crosses capillaries in these areas independently of and much more rapidly than albumin and other proteins having similar distribution kinetics. The lymph: plasma ratios for all the T4-binding proteins including albumin were very similar in any one area showing that the relative fractional rates of transcapillary movement of these proteins were very similar.

Therefore in extrahepatic areas, transcapillary movement of $\mathrm{T} 4$ in the protein-bound form was quantitatively much less important than in the free form. The findings support earlier views, recently questioned, that free T4 is of considerable physiological significance.

\section{INTRODUCTION}

For many years it has been thought that thyroxine (T4) traveled from plasma to the tissues as the unbound amino acid, so that the concentration of free $\mathrm{T} 4$ in plasma regulated the rate at which $\mathrm{T} 4$ became available to cells, for example in peripheral tissues and anterior pituitary (1). Consequently free T4 was considered to play a pivotal role in hormonal action and regulation and its

Received for publication 20 March 1973 and in revised form 5 September 1973.

${ }_{1}^{1}$ Abbreviations used in this paper: ISF, interstitial fluid; TGB, T4-binding globulin; T3, triiodothyronine; T4, thyroxine. plasma measurement was believed to provide a very useful index of thyroid hormone status. However, in 1967 Oppenheimer, Bernstein, and Hasen (2) published results of experiments from which they concluded that $\mathrm{T} 4$ leaves the plasma bound to proteins with transport kinetics the same as those of albumin.

Several aspects of their work have been supported by the results of other workers (4-6) while others have disagreed (7). However no direct measurements of the relative rates of transcapillary movement of $\mathrm{T} 4$ and albumin have yet been made. This report contains such measurements from several areas and tissues in the sheep obtained by sampling lymph from chronic fistulas in small lymphatics draining from defined pools of interstitial fluid, and in larger lymphatics draining less homogenous areas. Consequently we could compare the relative rates at which $\mathrm{T} 4$ and albumin leave the plasma in skin, lower leg, intestine, and liver. Since we were able to confirm experimentally the hypothesis of Oppenheimer et al. (2) that albumin and T4-binding proteins move from plasma to interstitial fluid (ISF) at similar fractional rates, we were able to measure the relative amounts of $\mathrm{T} 4$ which leave the circulation in the areas studied as free $\mathrm{T} 4$ and $\mathrm{T} 4$ bound to protein.

\section{METHODS}

Experimental animals were adult Merino sheep weighing $35-40 \mathrm{~kg}$. No differences in results due to sex were noted and so the results from male, female, and de-sexed sheep were grouped together. The sheep were kept in metabolism cages which gave them sufficient space to move back and forth a pace or two, to stand, sit, or lie; but the space was insufficient for them to turn completely around. Catheters were placed in the hepatic and intestinal lymph ducts in four sheep using the method of Lascelles and Morris (8) and in the popliteal duct by the method of Hall and Morris (9). Four sheep were prepared with popliteal fistulas only, while two had intestinal fistulas only. In three sheep a sub- 
cutaneous lymphatic accompanying the recurrent tarsal vein was cannulated, while in two a lymphatic draining the gastrocnemius muscle was cannulated. The relative contribution of skin and muscle to the lymph collected from these afferent lymphatics was approximated from the amount of Evans blue dye (T-1824) in the lymph after the injection of dye into either tissue. The dye had disappeared from lymph before the experiment commenced. These lymphatic fistulas permitted sampling of ISF which is in free contact with lymph through incompletely walled lymphatics. All operations were carried out under aseptic conditions and thiopentone-Fluothane anesthesia. The sheep tolerated the operations and the presence of the cannulas very well, and they were eating, drinking, and otherwise behaving normally within $4-8 \mathrm{~h}$ of surgery. Diet and general management were as described earlier (10).

1-2 days after operation, $15 \mu \mathrm{Ci}$ of $\left[{ }^{125} \mathrm{I}\right] \mathrm{T} 4$ and $10 \mu \mathrm{Ci}$ of $\left[{ }^{131} \mathrm{I}\right]$ human serum albumin (The Radiochemical Centre, Amersham, England), purified by dialysis (10), was given. The tracers contained no iodide, $1.5-2.0 \%$ of the ${ }^{125} \mathrm{I}$ as triiodothyronine (T3) plus reverse T3, and the remainder as T4. If sheep which had received human serum albumin once were used again, ${ }^{131}$ I-labeled bovine serum albumin (11) was used to avoid the accelerated immune clearance of a second injection. Blood samples were collected frequently from $2 \mathrm{~min}$ to $96 \mathrm{~h}$ after the injection as previously described (10). Hepatic and intestinal lymph samples were collected at 15-min intervals for the first $2 \mathrm{~h}$, and then at $30-\mathrm{min}$ intervals until the end of the experiment. Leg lymph was collected at 30 -min intervals. Powdered heparin was used as an anticoagulant for all samples. In one experiment a sheep with multiple hind leg fistulas was given $4 \mathrm{mg} \mathrm{T} 430 \mathrm{~h}$ after the isotopes were injected, by which time the specific activity of the labeled compounds in the extracellular fluids had come almost to equilibrium; plasma and lymph samples were then collected at 30 -min intervals for $2 \mathrm{~h}$.

Radioactivity in plasma and lymph was measured with a Packard 2 channel Autogamma Spectrometer (Packard Instrument Co., Inc., Downers Grove, Ill.), before and after precipitation of the proteins with trichloroacetic acid (TCA). In each experiment about six samples of plasma and of lymph from each route were taken at spaced intervals for chromatography. After adding $5 \mu \mathrm{g}$ propylthioura$\mathrm{cil} / \mathrm{ml}$, which is sufficient to prevent oxidation without introducing artifacts (12), the samples were extracted twice with 3 vol of acid butanol. 6 vol of chloroform was added to the pooled butanol extracts and was washed three times with $3 \mathrm{vol}$ of aqueous $2 \mathrm{M}$ ammonia. The ammonia washes, which contained $93-100 \%$ of the initial ${ }^{125} \mathrm{I}$, were dried at $30^{\circ} \mathrm{C}$ in vacuo, redissolved in methanol: ammonia, and chromatographed (together with standards) descending on paper in tertiary pentanol: ammonia and in collidine: water in an atmosphere containing ammonia (10).

T4 in several samples of plasma and lymph from each route was measured by column chromatography using the C: T4 Kitset (Curtis Nuclear Corp., Chemical Div., Los Angeles, Calif.). In later experiments total $\mathrm{T} 4$ was measured by competitive protein binding with correction for the ethanol extractable T4-binding substance (13). Albumin was measured in all samples of plasma and lymph by the method of Debro, Tarver, and Korner (14). Free T4 and the capacities and association constants of T4-binding proteins were measured by a method which depends on the property of Sephadex G-25 to bind T4 (15). When $500 \mathrm{mg}$ Sephadex was added as dry grains to $4 \mathrm{ml}$ of an appropriate dilution of the serum or lymph under test with added tracer $\mathrm{T} 4$, an equilibrium was reached rapidly in which the fraction, free $\left[{ }^{125} \mathrm{I}\right] \mathrm{T} 4$ in the $2.95 \mathrm{~g}$ aqueous phase/[ $\left.{ }^{125} \mathrm{I}\right] \mathrm{T} 4$ Sephadex bound, was 0.122 . The fraction was unaffected by the amount of protein or stable $\mathrm{T} 4$ in the system, although these factors greatly influenced [ $\left.{ }^{125} \mathrm{I}\right] \mathrm{T} 4$ protein bound. [ $\left.{ }^{125} \mathrm{I}\right] \mathrm{T} 4$ Sephadex bound was calculated as: total $\left[{ }^{125} \mathrm{I}\right] \mathrm{T} 4$ in the system minus $\left[{ }^{125} \mathrm{I}\right] \mathrm{T} 4$ in the aqueous phase which included protein-bound and free $\left[{ }^{125} \mathrm{I}\right] \mathrm{T} 4$. Free $\left[{ }^{125} \mathrm{I}\right]-$ $\mathrm{T} 4=\left[{ }^{125} \mathrm{I}\right] \mathrm{T} 4$ Sephadex bound $\times 0.122$. Protein-bound $\left[{ }^{125} \mathrm{I}\right]-$ $\mathrm{T} 4=\left[{ }^{125} \mathrm{I}\right] \mathrm{T} 4$ in the aqueous phase minus free $\left[{ }^{225} \mathrm{I}\right] \mathrm{T} 4$. Free T4 was calculated for undiluted serum as described elsewhere (15). To measure capacities and association constants of T4-binding proteins, this assay was repeated after addition of increasing amounts of stable $\mathrm{T} 4$ and the protein-bound and free $\mathrm{T} 4$ concentrations were determined at several concentrations of $\mathrm{T} 4$ in the system and plotted on logarithmic axes (Fig. 2). Because the curve of bound against free for each lymph pool is parallel with that for plasma, it is obvious that when one lymph pool is compared with plasma, at every free $\mathrm{T} 4$ concentration, $[F]$, the lymph:plasma ratio for bound $\mathrm{T} 4$ is the same. In this system:

$$
\begin{aligned}
\frac{b}{B}= & c_{1} \frac{K_{1}[F]}{1+K_{1}[F]}+c_{2} \frac{K_{2}[F]}{1+K_{2}[F] \ldots}+c_{\mathrm{n}} \frac{K_{\mathrm{n}}[F]}{1+K_{\mathrm{n}}[F]} \\
& C_{1} \frac{K_{1}[F]}{1+K_{1}[F]}+c_{2} \frac{K_{2}[F]}{1+K_{2}[F] \ldots}+C_{\mathrm{n}} \frac{K_{\mathrm{n}}[F]}{1+K_{\mathrm{n}}[F]}
\end{aligned}
$$

where $b$ and $B$ denote protein-bound T4 in lymph and plasma respectively, $c_{t}$ and $C_{t}$ are capacities of binding proteins in lymph and plasma, and $K_{t}$ is the association constant of protein . Because the binding proteins have very different association constants the term $K_{1}[F] /\left(1+K_{1}[F]\right)$ cannot remain proportional to $K_{2}[F] /\left(1+K_{2}[F]\right)$ as $[F]$ changes. Side $b / B$ is constant at all values of $[F]$, the capacities of the various binding proteins in lymph and in plasma must be in the same constant proportion; $c_{1} / C_{1}=c_{2} / C_{2}=c_{\mathrm{n}} / C_{\mathrm{n}}$ $=b / B=c_{a} / C_{a}$, where $a=$ albumin. Thus the lymph: plasma ratio for any binding protein is identical to that for albumin in any given lymph pool. It would have been much simpler and more acceptable to others who study $\mathrm{T} 4$-protein relationships if the conventional electrophoresis method had been used. This was initially done but it soon became evident that this method, which is run at nonphysiological temperature, ionic strength, buffer composition, and $\mathrm{pH}$ gives imprecise results which bear little relationship to the in vivo situation (15). The Sephadex method is extremely simple, highly reproducible and accurate, and gives results which are directly referable to the in vivo situation. In this paper it has been used to determine the relationships between the binding capacities of proteins in several pools. The exact capacities and association constants of each binding protein may also be found from 15 to 20 values of protein-bound and free T4 using either a curve-fitting procedure on a modified Scatchard plot (16) or a proportional graph method (17).

\section{RESULTS}

No labeled compounds other than those injected and iodide were found in any of the body fluids examined. In sheep brought to isotopic equilibrium by prolonged $\left[{ }^{125} \mathrm{I}\right]$ iodide administration, $19 \%$ of the plasma ${ }^{125} \mathrm{I}$ was as butanol nonextractable iodoprotein containing iodothy- 

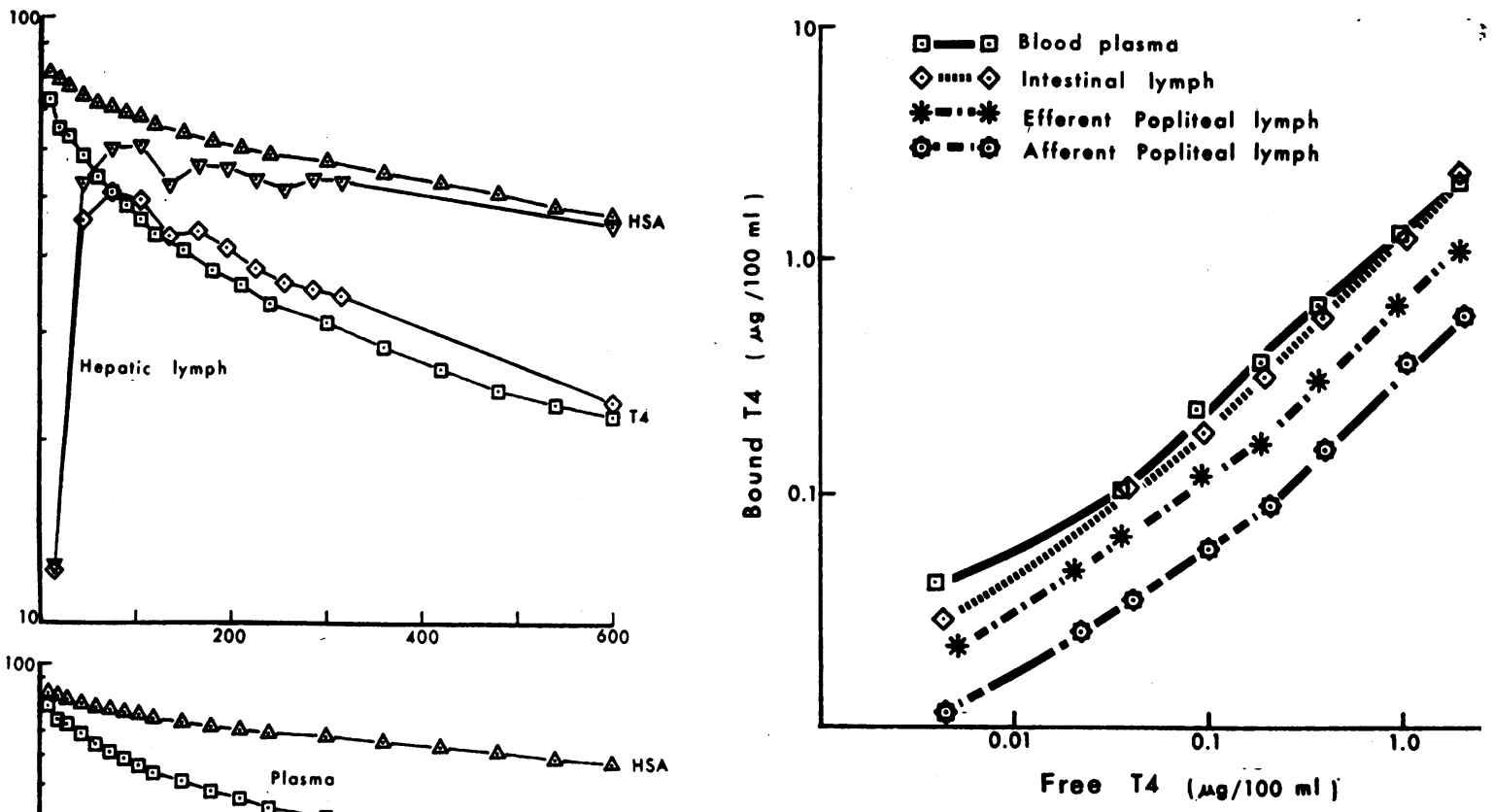

FIGURE 2 Concentration of free and bound $\mathrm{T} 4$ in dilute plasma and lymph from various areas after addition of increasing amounts of stable $\mathrm{T} 4$.

ronine in covalent linkage (18). Only $3.1 \pm 0.9 \%$ was found as butanol nonextractable material $72 \mathrm{~h}$ after $\left[{ }^{225} \mathrm{I}\right] \mathrm{T} 4$ in these sheep and since the plasma/lymph distribution was similar to that for $\mathrm{T} 4$, it was ignored. However the labeled T3 present as tracer contaminants appeared at a high concentration in the $0-0.5-\mathrm{h}$ lymph samples being $14 \%$ of the organic ${ }^{125} \mathrm{I}$ in popliteal lymph and $9.3 \%$ in intestinal lymph. The percentage fell to less than $2 \%$ by $2.5 \mathrm{~h}$. Chromatography was not done on some early samples because of low counts. However in each sheep studied the $\mathrm{T} 3: \mathrm{T} 4$ ratio in the tracer regulated the T3: T4 ratio in each lymph bed in a consistent and predictable way. Where chromatography data were not available for a particular lymph sample, correction was made on this basis (see footnote 2). In all other samples TCA-precipitable ${ }^{128} \mathrm{I}$ and ${ }^{181} \mathrm{I}$ were taken to represent $\mathrm{T} 4$ and albumin respectively, and are quoted throughout. The levels of both labeled substances in

${ }^{2}$ For the missing values the T3:T4 ratio in the tracer was obtainable as the T3:T4 ratio in the dose multiplied by the factor given below:

\begin{tabular}{ccc}
\hline Time (h) & $\begin{array}{c}\text { Intestinal } \\
\text { lymph }\end{array}$ & $\begin{array}{c}\text { Popliteal } \\
\text { lymph }\end{array}$ \\
\hline $0-0.5$ & 4.6 & 7 \\
$0.5-1.0$ & 3.2 & 5.3 \\
$1.5-2.0$ & 1.6 & 1.8 \\
$2.0-2.5$ & 0.9 & 1.2 \\
$>2.5$ & $<1$ & $<1$ \\
\hline
\end{tabular}


TABLE I

Specific Activity of Lymph/Mean Specific Activity of Plasma Over Collection Period at Selected Times

\begin{tabular}{|c|c|c|c|c|c|c|c|}
\hline \multirow[b]{2}{*}{ Time } & \multicolumn{3}{|c|}{$\mathrm{T} 4$} & \multicolumn{3}{|c|}{ Albumin } & \multirow[b]{2}{*}{$\begin{array}{c}\text { Lymph: plasma T4/ } \\
\text { Lymph: plasma albumin }\end{array}$} \\
\hline & $\begin{array}{l}\text { Sp act } \\
\text { lymph }\end{array}$ & $\begin{array}{l}\text { Sp act } \\
\text { plasma }\end{array}$ & $\begin{array}{c}\text { Sp act lymph/ } \\
\text { sp act plasma }\end{array}$ & $\begin{array}{l}\text { Spact } \\
\text { lymph }\end{array}$ & $\begin{array}{l}\text { Sp act } \\
\text { plasma }\end{array}$ & $\begin{array}{l}\text { Sp act lymph/ } \\
\text { sp act plasma }\end{array}$ & \\
\hline \multicolumn{8}{|l|}{$h$} \\
\hline \multicolumn{8}{|l|}{ Hepatic } \\
\hline 0.1 & 1.01 & 1.31 & 0.782 & 1.82 & 2.53 & 0.719 & 1.088 \\
\hline $1.5-2.0$ & 0.962 & 0.958 & 1.003 & 1.94 & 2.27 & 0.856 & 1.171 \\
\hline $3.0-3.5$ & 0.858 & 0.776 & 1.106 & 1.87 & 2.04 & 0.917 & 1.219 \\
\hline $5.0-5.5$ & 0.714 & 0.636 & 1.123 & 1.77 & 1.88 & 0.940 & 1.194 \\
\hline $10.0-10.5$ & 0.482 & 0.453 & 1.062 & 1.40 & 1.54 & 0.906 & 1.172 \\
\hline \multicolumn{8}{|l|}{ Intestinal } \\
\hline $0.5-1.0$ & 0.232 & 1.22 & 0.191 & 0.062 & 2.45 & 0.0251 & 7.64 \\
\hline $1.5-2.0$ & 0.412 & 0.958 & 0.430 & 0.140 & 2.27 & 0.0616 & 6.98 \\
\hline $2.5-3.0$ & 0.596 & 0.827 & 0.721 & 0.246 & 2.10 & 0.117 & 6.16 \\
\hline $5.5-6.0$ & 0.560 & 0.610 & 0.918 & 0.403 & 1.85 & 0.218 & 4.21 \\
\hline $9.5-10.0$ & 0.483 & 0.464 & 1.04 & 0.749 & 1.59 & 0.471 & 2.21 \\
\hline $13.5-14.0$ & 0.381 & 0.387 & 0.984 & 0.769 & 1.40 & 0.549 & 1.79 \\
\hline $25.5-26.0$ & 0.219 & 0.227 & 0.966 & 0.950 & 1.027 & 0.925 & 1.044 \\
\hline \multicolumn{8}{|l|}{ Popliteal } \\
\hline $0-0.5$ & 0.071 & 1.44 & 0.049 & 0.034 & 2.64 & 0.0130 & 3.80 \\
\hline $0.5-1.0$ & 0.212 & 1.22 & 0.173 & 0.140 & 2.45 & 0.0573 & 3.03 \\
\hline $1.0-1.5$ & 0.210 & 1.06 & 0.199 & 0.204 & 2.35 & 0.087 & 2.28 \\
\hline $2.0-2.5$ & 0.200 & 0.822 & 0.226 & 0.284 & 2.17 & 0.131 & 1.73 \\
\hline $10.0-11.0$ & 0.324 & 0.448 & 0.723 & 0.637 & 1.52 & 0.419 & 1.73 \\
\hline $17.0-18.0$ & 0.302 & 0.330 & 0.915 & 0.790 & 1.26 & 0.627 & 1.46 \\
\hline $24.0-25.0$ & 0.257 & 0.240 & 1.073 & 0.811 & 1.056 & 0.768 & 1.39 \\
\hline $31.0-32.0$ & 0.240 & 0.187 & 1.286 & 0.885 & 0.926 & 0.956 & 1.35 \\
\hline $44.0-45.0$ & 0.173 & 0.140 & 1.234 & 0.805 & 0.805 & 1.000 & 1.23 \\
\hline $59.0-60.0$ & 0.130 & 0.101 & 1.286 & 0.859 & 0.765 & 1.123 & 1.14 \\
\hline
\end{tabular}

plasma and lymph, relative to the amount injected, followed similar time courses in all experiments. Results from typical experiments are shown in Figs. 1 and 2.

In Table I, data from all the experimental sheep are tabulated for representative intervals, and are expressed as the sp act in lymph and in plasma during each collection period for both T4 and albumin. The lymph: plasma ratio for each substance is given to show the rate at which each ISF pool exchanges with plasma. For any ISF pool these ratios were remarkably constant from sheep to sheep.

Labeled T4 disappeared from the plasma much more rapidly than albumin, and appeared in lymph much more rapidly than albumin in all areas studied except liver. Equilibration between plasma and ISF as judged by the attainment of a constant lymph: plasma sp act ratio occurred in the intestinal pool by $8 \mathrm{~h}$ for T4 and $26 \mathrm{~h}$ for albumin; and in the mixed leg and skin pools by $32 \mathrm{~h}$ for $\mathrm{T} 4$ and $60 \mathrm{~h}$ for albumin. In the liver, $\mathrm{T} 4$ equilibrated by $2 \mathrm{~h}$, whereas the equilibration of albumin was slightly slower; this difference could be due to experimental error.

Consistently good flow was not obtained from lymphatics carrying the highest concentration of dye after the injection of Evans blue. It was possible to measure the concentrations of stable and labeled albumin and $\mathrm{T} 4$ in lymph derived largely from muscle and these were slightly below those of mixed popliteal lymph. In one experiment, a small afferent lymphatic, which seemed to carry mixed muscle and skin lymph as judged by the dye intensity, protein, and $\mathrm{T} 4$ concentrations gave a lymph: plasma ratio for T4 2.4 times that for albumin for the $1 \mathrm{st} h$. Since the difference was usually much less marked in lymph derived from skin it seems that the lymph derived from muscle would have an initial ratio in excess of 3. Mixed popliteal lymph is derived largely from skin and muscle but might be modified slightly on passage through the lymph node.

The lymph: plasma ratios for stable $\mathrm{T} 4$ and albumin, respectively in the pools sampled were: hepatic, 1.0 and 
TABLE II

Effect of $4 \mathrm{mg}$ T4 i.v. Given $29.5 \mathrm{~h}$ after $\left[{ }^{125} \mathrm{I}\right] \mathrm{T} 4$ and $\left[{ }^{131} \mathrm{I}\right]$ Albumin

\begin{tabular}{|c|c|c|c|c|c|c|c|}
\hline \multirow[b]{2}{*}{ Time } & \multicolumn{2}{|c|}{ Plasma } & \multicolumn{2}{|c|}{ Afferent popliteal lymph } & \multicolumn{2}{|c|}{ Lymph: plasma ratio } & \multirow{2}{*}{$\begin{array}{l}\text { Lymph: plasma T4/ } \\
\text { Lymph: plasma albumin }\end{array}$} \\
\hline & $\mathrm{T} 4$ & Albumin & $\mathrm{T} 4$ & Albumin & $\mathrm{T} 4$ & Albumin & \\
\hline$h$ & \multicolumn{2}{|c|}{$\%$ dose/liter } & \multicolumn{2}{|c|}{$\%$ dose/liter } & \multicolumn{2}{|c|}{$\%$ dose/liter } & \\
\hline 25.5 & 19.89 & .47 .28 & 7.08 & 11.13 & 0.356 & 0.236 & 1.51 \\
\hline 27.5 & 19.32 & 47.00 & 6.78 & 11.33 & 0.351 & 0.241 & 1.46 \\
\hline 29.5 & 18.76 & 46.71 & 6.54 & 11.93 & 0.349 & 0.255 & 1.37 \\
\hline 29.75 & 15.95 & 47.11 & 5.96 & 10.68 & 0.374 & 0.227 & 1.64 \\
\hline 30.15 & 14.97 & 46.55 & 6.28 & 11.21 & 0.420 & 0.241 & 1.74 \\
\hline 30.75 & 14.75 & 46.40 & 6.11 & 10.97 & 0.414 & 0.236 & 1.75 \\
\hline
\end{tabular}

0.98 ; intestinal, 0.73 and 0.79 ; popliteal, 0.39 and 0.40 ; skin, 0.29 and 0.31 These ratios were also very constant between sheep, except for intestinal lymph in which T4 and albumin concentrations varied inversely with flow rate. Because most of the T4 in plasma and lymph was expected to be protein bound, it seemed likely from the above ratios that in any one animal the lymph: plasma ratio for T4-binding proteins would be similar to that for albumin. This was confirmed experimentally using the Sephadex method.

Although the concentration of total $\mathrm{T} 4$ varied considerably in the fluids studied, in any animal the concentration of free T4 in undiluted plasma and lymph from any area was similar. This means that in any tissue fluid, the fraction of the total T4 which was free was related inversely to the total $\mathrm{T} 4$ concentration, increasing from about $0.075 \%$ for plasma to about $0.25 \%$ for afferent popliteal lymph. When $4 \mathrm{mg}$ T4 was injected $29.5 \mathrm{~h}$ after the tracers, the plasma concentration of labeled T4 fell by $2.81 \%$ of the dose/liter per $15 \mathrm{~min}$, which was 40 times the preinjection rate, during the first $15 \mathrm{~min}$ after the injection, and continued to fall rapidly for the next $1 \frac{1}{2} \mathrm{~h}$; there was no change in the rate of removal of labeled albumin from the circulation (Table II). Concurrently there was a steady increase of approximately $30 \%$ in the labeled T4/albumin lymph: plasma ratio which had been falling very slightly at this time.

\section{DISCUSSION}

The transcapillary movement of the protein which binds T4 most avidly, usually called T4-binding globulin (TBG), has not been studied directly because it has not been purified and labeled satisfactorily. However, we have been able to show that in the sheep, for lymph coming from various regions, the lymph: plasma ratio for TBG and other T4-binding proteins is very similar to that for albumin. In comparing the movement of two macromolecular substances in any body region, Renkin (19) has shown that there is a linear relationship be- tween the fractional rate of outward transcapillary movement of each substance and the lymph/plasma concentration of each substance in that region. In the present experiments, in each body region, the lymph/plasma concentration of each T4-binding protein was the same as albumin. Therefore their outward rates of transcapillary movement are the same as albumin. This agrees with the conclusions of Oppenheimer et al. (2) based on the very similar plasma disappearance curves for labeled albumin and prealbumin.

Our results show a much greater fractional flux of plasma T4 than of albumin into the ISF of extrahepatic areas being sampled by lymphatic cannulation. Clearly, T4 passes from plasma to lymph largely independent of and more rapidly than its binding proteins. These findings are in accord with the suggestion (20) that T4 leaves the circulation as free $\mathrm{T} 4$ which is in equilibrium with $\mathrm{T} 4$ bound to proteins and that upon entering the ISF it equilibrates with protein again according to the law of mass action. Unlike macromolecules, small unbound molecules such as the free $\mathrm{T} 4$ fraction can also pass across the capillary wall in an inward direction. Fig. 1 shows that there was an initial steep early rise in popliteal lymph followed by a flattening off of the curve; $32 \mathrm{~h}$ was required to attain the same slope as the plasma, which is not a great deal faster than the $60 \mathrm{~h}$ for albumin equilibration. Thus the initial part of the curve might be taken to indicate that for $\mathrm{T} 4$, as compared with albumin, equilibration between popliteal lymph and plasma is a rapid process, whereas the later part of the curve shows that equilibration of $\mathrm{T} 4$ is relatively slow. The pattern is similar with intestinal lymph although the inconsistency between early and late equilibration rates is less obvious. Using the plasma $\left[{ }^{25} \mathrm{I}\right] \mathrm{T} 4$ values as the generating source, it was not possible to reproduce the observed lymph concentrations in any second compartment using feasible rates of uni- or bidirectional exchange with plasma. However if a third compartment linked in series beyond ISF and exchanging uni- or bidirectionally with it was included, results for compart- 
ment 2, identical with those observed experimentally for lymph, could be reproduced using credible transfer rates (see Appendix). This is physiologically compatible with the plasma, ISF, and cellular compartments linked in series. The simplest scheme which can describe these plasma and ISF concentrations of labeled $\mathrm{T} 4$ and albumin requires: ( $a$ ) plasma to ISF movement of free T4, (b) plasma to ISF movement of proteinbound $\mathrm{T} 4$ and albumin, $(c)$ transcapillary ISF to plasma movement of free $\mathrm{T} 4,(d)$ ISF to cell movement of T4, (e) cell to ISF movement of T4. The latter has been shown to occur (21). If the amount of protein-bound $\mathrm{T} 4$ moving outwards across the capillary greatly exceeded the amount moving by means of $(a),(c)$, and $(d)$, then the fraction of the plasma $\mathrm{T} 4$ and albumin passing to lymph during even the earliest collection times would be the same. This occurs in hepatic lymph indicating that virtually all $\mathrm{T} 4$ moves bound to protein. In any situation the amount moving by means of $(c)$, plus the excess of $(d)$ over $(e)$ would reduce the amount of labeled T4 in lymph compared with albumin, which is not lost from lymph by $(c)$ and $(d)$. However since labeled $\mathrm{T} 4$ in popliteal and intestinal lymph, expressed as a fraction of the plasma $\mathrm{T} 4$ concentration, greatly exceeds that of albumin in the first collections, plasma to ISF movement as free T4 must greatly exceed that bound to protein. This is believed to be the mechanism of the initial steep rise in the $\left[{ }^{125} \mathrm{I}\right] \mathrm{T} 4$ popliteal lymph curve. Nevertheless as long as the amount of $\left[{ }^{125} \mathrm{I}\right] \mathrm{T} 4$ lost from ISF into cells exceeds that returned from cells, the net loss of $\left[{ }^{225} \mathrm{I}\right] \mathrm{T} 4$ from ISF into cells will cause the sp act of T4 in ISF to be below its final equilibrium relationship with plasma. In general the movements of substances into and out of tissues cells such as muscle, skin, and bone, and equilibration in the intracellular pool have a slower fractional rate than transcapillary movement. This will delay the equilibration of $\left[{ }^{125} \mathrm{I}\right] \mathrm{T} 4$ between plasma and popliteal lymph. Thus the attainment of equilibrium distribution of $\left[{ }^{125} \mathrm{I}\right] \mathrm{T} 4$ between $\mathrm{ISF}$ and plasma may require almost as long as for protein which moves much more slowly in one direction between these two compartments only.

In hind leg lymph the early lymph:plasma sp act ratio of T4 was 3.8 times that of albumin, so that the fractional rate of outward transcapillary movement of T4 would be over four times as high as that of its binding proteins. Therefore over three times as much T4 crossed the capillary wall independent of its binding proteins as did $\mathrm{T} 4$ bound to protein. If this excess represents the movement of free $\mathrm{T} 4$, which is approximately $0.05-0.10 \%$ of the total plasma $\mathrm{T} 4$, then it may be calculated that the fractional rate of transcapillary movement of free T4 is more than 4,000 times (viz. $3 \times$ $100 / 0.075$ ) that of its binding proteins or of albumin.
This figure may be compared with fractional rates of transcapillary movement in the hind leg of the cat of 4,000 for sucrose and 3,000 for raffinose, relative to albumin, substances with unhydrated molecules smaller and larger respectively than those of T4 (22). For the intestinal circulation our data show that the fractional rate of transcapillary movement of free $\mathrm{T} 4$ is more than 14,000 times that of albumin. These figures indicate that although only a small proportion of $\mathrm{T} 4$ in plasma is not bound to protein, most $\mathrm{T} 4$ leaves the circulation in extrahepatic tissues as free T4. In the liver the apparent fractional rate of movement of $\mathrm{T} 4$ from plasma to lymph was not measurably different from that of albumin over the period during which sufficient lymph could be collected for reliable assay. This suggests that the amount of T4 moving in the free, as compared with the proteinbound form is too small to be measurable experimentally. This is probably due to the incomplete endothelium of liver sinusoids. It seems that $\mathrm{T} 4$ can move through the capillary wall by pathways which restrain albumin; also these pathways are more frequent, or permeable, in intestinal than in muscle and skin capillaries. It may be relevant that the capillary basement membrane is "incomplete" in the liver, "fine but complete" in intestinal capillaries, and "fairly dense" in muscle and skin capillaries. Parallel differences exist in the structure of the capillary cell itself (23).

Several other of our results provide supporting evidence that the fractional rate of movement of $\mathrm{T} 4$ across capillary walls in extrahepatic tissues is greater than that of albumin. The fractional rate of removal of labeled T4 from blood was greater than that of albumin long after the liver had ceased to take up labeled T4. Also, when a loading dose of unlabeled $\mathrm{T} 4$ was given to a sheep in which labeled T4 and albumin had almost equilibrated between blood and tissues, there was an initial rapid decrease of $\left.{ }^{[25} \mathrm{I}\right] \mathrm{T} 4$ in blood and after a 15-min delay, a decrease in the rate of decline of $\left[{ }^{125} \mathrm{I}\right] \mathrm{T} 4$ in popliteal lymph, while the levels of labeled albumin did not change. The initial effect of the unlabeled T4, which would have increased the proportion of free $\mathrm{T} 4$ in the blood considerably, supports the thesis that $\mathrm{T} 4$ leaves the circulation as free T4.

Since rates of transcapillary movement of $\mathrm{T} 4$ and the role of free $\mathrm{T} 4$ in regulating hormone metabolism are of considerable interest in man, it is appropriate to consider certain similarities and differences in T4 transport in man and sheep. Of all experimental or domestic animals the sheep most closely resembles man in its pattern of specific binding proteins with similar association constants. Although the capacities of these proteins and levels of plasma T4 are about $40-50 \%$ lower in the sheep than in man and although the free T4 percentage of 0.075 is approximately twice as high, the absolute con- 
centration of free $\mathrm{T} 4$ is very similar to that of man. Furthermore the degradation of $\mathrm{T} 4$ for equal metabolic mass is almost the same in the sheep and man (10), and the concentration of albumin in plasma and its turnover, after correction for gut loss, are very similar in sheep and man (C. H. G. Irvine, unpublished data). These close similarities between man and sheep should justify the use of the sheep to investigate problems not approachable experimentally in man in whom direct sampling of extravascular fluid in normal subjects is impracticable. Nevertheless the conclusion that T4 moves across the capillary wall mainly in the free form, with the movement of protein-bound T4 having relatively little effect on distribution kinetics, is in direct contrast to that of Oppenheimer et al. $(2,3)$. However their conclusions are based on a single experiment using unpurified tracer in which the only extravascular fluid sampled was the abnormal pleural effusion of a $65-\mathrm{yr}$ old man with congestive heart failure in whom the initial plasma albumin clearance was three times normal.

Some confirmation of our work is provided by experiments in man $(5,24)$ in which the uptake of $\left[{ }^{131} \mathrm{I}\right] \mathrm{T} 4$ by the liver after i.v. injection has been measured by an external probe, and the extrahepatic uptake obtained by difference. Unfortunately, unpurified tracer was used in each case and the early uptake reflected extravascular distribution of poorly bound radioactive contaminants such as iodide and $\mathrm{T} 3$ which form over $14 \%$ of the ${ }^{131} \mathrm{I}$ in this tracer (25). When control subjects were compared those with a low free $\mathrm{T} 4$ fraction during the period 30-90 min, by which time contaminants should be largely distributed in extravascular spaces, the uptake of ${ }^{131}$ I by extrahepatic areas was only slightly lower in the group with a low free T4 fraction (6.8 compared with $8.0)$. However because the loss of $\left[{ }^{131} \mathrm{I}\right] \mathrm{T} 4$ from plasma was slower in the low free $\mathrm{T} 4$ group, the mean plasma concentration of $\left.{ }^{181} \mathrm{I}\right] \mathrm{T} 4$ was higher $(62.4 \%$ of dose in plasma over 30-90 min compared with 56.0 in controls) so that the fractional transfer from plasma to extrahepatic tissue in the low free T4 group was $0.109 \%$ of the dose per $\mathrm{h}$ compared with 0.143 in controls (24). Similar results may be obtained using data from the only other time intervals available, 120 and $180 \mathrm{~min}$. It may be similarly calculated from the data of Cavalieri and Searle (5) that subjects with a high free T4 fraction had a significantly higher fractional transfer rate from plasma to extrahepatic tissue. In an attempt to overcome some of the difficulties of interpreting the above experiments Cavalieri, Steinberg, and Searle (26) used a continuous infusion of purified tracer to maintain a constant plasma concentration while monitoring radioactivity over the thigh. Although $\left[{ }^{131} \mathrm{I}\right] \mathrm{T} 3$ was substituted for $\left[{ }^{121} \mathrm{I}\right] \mathrm{T} 4$, free $\mathrm{T} 3$ not being measured, its level was inferred from differences in the free $\mathrm{T} 4$ index between groups. Because subjects with a high free $\mathrm{T} 3$ fraction do not show a greater increment than normals when the thigh or extrahepatic uptake at 30 or $60 \mathrm{~min}$ is expressed as a fraction of the 10 or 20 min uptake, they concluded that the rate of diffusion of $\mathrm{T} 3$ into such tissues is relatively insensitive to the free hormone level. However, if an elevated free $\mathrm{T} 3$ did cause a more rapid tissue uptake, as we believe, the increase would be greatest in the earliest measurements but would not be shown when a later uptake is divided by an earlier uptake as done by Cavalieri et al. For example in our experiments when a rapidly moving tracer such as $\left.{ }^{125} \mathrm{I}\right] \mathrm{T} 4$ was compared with a slower one such as $\left[{ }^{131} \mathrm{I}\right]$ albumin, the lymph: plasma ratio for $\left[{ }^{125} \mathrm{I}\right] \mathrm{T} 4$ at $30 \mathrm{~min}$ was 3.8 times that for $\left[{ }^{131} \mathrm{I}\right]$ albumin (Table I). However if the amounts in lymph at longer intervals are expressed as a fraction of the earliest measurements, the results are lower for $\left[{ }^{125} \mathrm{I}\right] \mathrm{T} 4$ than for $\left[{ }^{191} \mathrm{I}\right]$ albumin; e.g. the $2.5 / 0.5 \mathrm{~h}$ value for $\left[{ }^{125} \mathrm{I}\right] \mathrm{T} 4$ was 4.6 and for $\left[{ }^{121} \mathrm{I}\right]$ albumin 10.1 even though the fractional clearance of $\mathrm{T} 4$ from plasma to lymph was much greater than albumin. For any substance which moves from plasma to extravascular areas and back, irrespective of how simple or complex its distribution through the extravascular area, the greater its fractional transfer rate to and from plasma the smaller will be the increments in extravascular uptake if they are expressed as the amount at a long time interval divided by the amount at a short time interval. Cavalieri et al. comment that the $20 \mathrm{~min}$ uptake of $\left.{ }^{[81} \mathrm{I}\right] \mathrm{T} 3$ into extrahepatic tissue correlated positively with the level of free hormone although the $60 \mathrm{~min} / 20 \mathrm{~min}$ fraction was $10 \%$ lower in subjects with the higher free fraction. While they explain this by postulating a "complexity of the kinetics of extrahepatic tissue uptake, with slowly equilibrating tissues being relatively insensitive to alterations in plasma binding," their results may be simulated by a single homogeneous extravascular compartment exchanging with plasma at a rate dependent on the level of free hormone and with a third homogeneous compartment in series. Although these and other workers have shown that there is a high correlation between liver uptake and the proportion of free hormone in plasma, the results in their Fig. 3 show that the 20 $\mathrm{min} / 5 \mathrm{~min}$ liver uptake ${ }^{3}$ is lower in the presence of a

\footnotetext{
${ }^{3}$ Because the liver equilibrates more rapidly than thigh, the shortest time interval available $(5 \mathrm{~min}$ ) was used and compared with a time when the uptake curve was becoming appreciably flatter thus giving conditions similar to those for thigh. Liver uptakes were obtained as described by Cavalieri and Searle (5) from (total counts per minute in the field of the probe minus counts per minute due to blood in the liver and other organs in the field of the probe). For normal subjects liver uptake rose from approximately $26 \%$ at $5 \mathrm{~min}$ to $47 \%$ at $20 \mathrm{~min}$ for the high free $\mathrm{T} 3$, and from 12 to $35 \%$ in the normal subjects, fractional increments of 0.8 and 1.9 , respectively.
} 
high free T3 than in normal subjects although the 5 min uptake is higher. Thus the thigh and liver uptake of Cavalieri et al. and the lymph uptake in our data show identical patterns and since in the latter two cases it is accepted that the higher level of free hormone causes the higher initial extravascular uptake with a lower fractional increment subsequently, it is likely that similar conditions operate in the thigh. While no definitive experimental measurements of the rate of transcapillary movement of $\mathrm{T} 4$ have been done in man, we believe that such evidence as is available supports our view that the rate of transcapillary movement of $\mathrm{T} 4$ into extrahepatic areas depends mainly on the free fraction.

\section{APPENDIX}

T4 movement into the thigh tissues was simulated using the Continuous Systems Modeling Program for the IBM 1130 computer. Data given in this paper and elsewhere (18) provide the following pool sizes and transfer rates per hour for T4 in sheep: plasma to ISF, 0.08; ISF to plasma (transcapillary), 0.1132; irreversible loss from ISF (lymph drainage), 0.04 ; ISF to tissue, 0.75 ; tissue to ISF, 1.858 irreversible loss from tissue (degradation), 0.017 ; pool sizes were plasma 1 , ISF 0.5 , tissue 0.2 . For albumin the transfer rate from plasma to ISF was one-quarter the rate for T4, namely 0.02 ; since $99.5 \%$ of the T4 in ISF is protein bound, lymph flow will remove the same fraction of albumin as of T4, namely 0.04 . All other transfer rates for albumin are zero. The thigh area accounts for only a fraction of the total loss of isotope and could not be used, together with plasma, as a self-contained system to produce the experimentally observed plasma disappearance curve. Therefore the experimental plasma levels for $\left[{ }^{25} \mathrm{I}\right]-$ T4 and [ ${ }^{131} \mathrm{I}$ ] albumin (Fig. 1 and Table I) at each $0.1 \mathrm{~h}$ time interval were used. With this model the $0-0.5 \mathrm{~h}$ lymph: plasma ratio for $\left[{ }^{125} \mathrm{I}\right] \mathrm{T} 4$ was 3.9 times that for $\left[{ }^{131} \mathrm{I}\right]-$ albumin consistent with the fourfold difference in plasma to lymph transfer, yet isotopic equilibration required $32 \mathrm{~h}$ for $\mathrm{T} 4$ and $64 \mathrm{~h}$ for albumin (isotopic equilibrium was regarded as being established when the lymph:plasma sp act ratio for the isotope changed by less than $1.0 \%$ over a 2 -h period). If the transfer rate from ISF to cells for T4 was altered to 0.12 and for cells to ISF to 0.283 without change in plasma-lymph transfer rates, equilibration between plasma and lymph required $44 \mathrm{~h}$ and the lymph: plasma ratio for $\left[{ }^{125} \mathrm{I}\right] \mathrm{T} 4$ and $\left[{ }^{131} \mathrm{I}\right]$ albumin was almost identical from $30 \mathrm{~h}$ onwards even though $\mathrm{T} 4$ was still crossing the capillaries four times as rapidly as albumin. This illustrates the unreliability of the equilibration time of ISF and plasma as an index of the rate of plasma to ISF movement of substances which behave differently in the extravascular area.

\section{REFERENCES}

1. Ingbar, S. H., and K. A. Woeber. 1968. The thyroid gland. In Textbook of Endocrinology. R. H. Williams, editor. W. B. Saunders Company, Philadelphia. 4th edition. 105.

2. Oppenheimer, J. H., G. Bernstein, and J. Hasen. 1967. Estimation of rapidly exchangeable cellular thyroxine from the plasma disappearance curves of simultaneously administered thyroxine ${ }^{-131} \mathrm{I}$ and albumin ${ }^{125} \mathrm{I}$. J. Clin. Invest. 46: 762-777.

3. Oppenheimer, J. H., M. I. Surks, and H. I. Schwartz. 1969. The metabolic significance of exchangeable cellular thyroxine. Recent Prog. Horm. Res. 25: 381-422.

4. Schussler, G. C. 1968. The extravascular circulation of thyroxine. Clin. Res. 16: 274. (Abstr.)

5. Cavalieri, R. R., and G. L. Searle. 1966. The kinetics of distribution between plasma and liver of ${ }^{131}$ I-labeled L-thyroxine in man: observations of subjects with normal and decreased serum thyroxine-binding globulin. J. Clin. Invest. 45 : 939-949.

6. Dowling, J. T., W. G. Appleton, and B. U. Musa. 1968. Direct measurement of hepatic thyroxine flux in normal man. J. Clin. Endocrinol. Metab. 28: 1503-1507.

7. Nicoloff, J. T., and J. T. Dowling. 1968. Estimation of thyroxine distribution in man. J. Clin. Invest. 47: 26-37.

8. I ascelles, A. K., and B. Morris. 1961. Surgical techniques for the collection of lymph from unanaesthetised sheep. Q. J. Exp. Physiol. 46: 199-205.

9. Hall, J. G., and B. Morris. 1962. The output of cells from the popliteal node of the sheep. Q.J. Exp. Phy'siol. $47: 360-369$.

10. Irvine, C. H. G. 1969. Qualitative and quantitative aspects of thyroxine metabolism in sheep. Endocrinology. 85 : $662-673$.

11. Helmkamp, R. W., R. L. Goodland, W. F. Bale, I. L. Spar, and L. E. Mutschler. 1960. High specific activity iodination of $\gamma$-globulin with iodine-131 monochloride. Cancer Res. 20: 1495-1500.

12. Dimitriadou, A., R. Fraser, and P. C. R. Turner. 1964. Iodotyrosine-like substances in human serum. Nature (Lond.). 201 : 575-578.

13. Irvine, C. H. G. 1974. The effect of an ethanol extractable thyroxine binding substance in plasma on the measurement of thyroxine by competitive. binding. $J$. Clin. Endocrinol. Metab. 38: 468-475.

14. Debro, J. R., H. Tarver, and A. Korner. 1957. The determination of serum albumin and globulin by a new method. J. Lab. Clin. Med. 50: 728-732.

15. Irvine, C. H. G. 1974. Measurement of free thyroxine in human serum by a Sephadex binding method. J. Clin. Endocrinol. Metab. 38: 655-662.

16. Scatchard, G. 1949. The attraction of proteins for small molecules and ions. Ann. N. Y. Acad. Sci. 51: 660-672.

17. Baulieu, E. E., and J-P. Raynaud. 1970. A "proportion graph" method for measuring binding systems. Eur. J. Biochem. 13: 293-304.

18. Irvine, C. H. G. 1974. Concentration of thyroxine in cellular and extracellular tissues of the sheep and the rate of equilibration of labelled thyroxine. Endocrinology. 94 : 1060-1076.

19. Renkin, E. M. 1968. Capillary Permeability. In Lymph and the Lymphatic System. H. S. Mayerson, editor. Charles C. Thomas, Publisher, Springfield, Ill. 76.

20. Robbins, J., and J. E. Rall. 1957. II. Hormone transport in circulation. Interaction of thyroid hormones and protein in biological fluids. Recent Prog. Horm. Res. 13: 161-208.

21. Gorman, C. A., E. V. Flock, C. A. Owen, Jr., and J. Paris. 1966. Factors affecting exchange of thyroid hormones between liver and blood. Endocrinology. 79: 391-405.

22. Landis, E. M., and J. R. Pappenheimer. 1963. Exchange of substances through capillary walls. Handb. Physiol. Circulation. 3 (Sect. 2) : 961-1034. 
23. Reeve, E. B., and A. Y. Chen. 1970. Regulation of interstitial albumin. In Plasma Protein Metabolism. M. A. Rothchild and T. Waldmann, editors. Academic Press, Inc., New York. 89-109.

24. Musa, B. U., R. S. Kumar, and J. T. Dowling. 1969. Role of thyroxine-binding globulin in the early distribution of thyroxine and triiodothyronine. J. Clin. Endocrinol. Metab. 29 : 667-674.

25. Volpert, E. M., M. Martinez, and J. H. Oppenheimer.
1967. Radioiodinated impurities in commercial preparations of ${ }^{181}$ I-thyroxine and their effect on the measurement of free thyroxine in human serum by equilibrium dialysis. J. Clin. Endocrinol. Metab. $27: 421-428$.

26. Cavalieri, R. R., M. Steinberg, and G. L. Searle. 1970. The distribution kinetics of triiodothyronine: studies of euthyroid subjects with decreased plasma thyroxinebinding globulin and patients with Graves' disease. $J$. Clin. Invest. 49 : 1041-1051. 